\title{
Analysis of sedimentary structures and accumulations in the dredging dump areas of the Port of Itajaí, Santa Catarina, using Side Scan Sonar images
}

\author{
Laura Teixeira do Nascimento; José Gustavo Natorf de Abreu(1); Mauro Michelena Andrade ${ }^{(2)}$; Luana Rebeca Machado \\ Lucas Ferreira da Silveira ${ }^{(3)}$; \\ (1) Geological Oceanography Laboratory, School of the Sea, Science and Technology, University of Vale do Itajaí \\ (GOL/SSST/Univali); gabreu@univali.br \\ (2) Physical Oceanography Laboratory, School of the Sea, Science and Technology, University of Vale do Itajaí \\ (POL/SSST/Univali; \\ (3) SLI Coastal Solution
}

Copyright 2021, SBGf - Sociedade Brasileira de Geofísica.

This paper was prepared for presentation during the $17^{\text {th }}$ International Congress of the Brazilian Geophysical Society held in Rio de Janeiro, Brazil, 8-11 November 2021.

Contents of this paper were reviewed by the Technical Committee of the $17^{\text {th }}$ International Congress of the Brazilian Geophysical Society and do not necessarily represent any position of

the SBGf, its officers or members. Electronic reproduction or storage of any part of this paper for commercial purposes without the written consent of the Brazilian Geophysical Society is prohibited.

\section{Abstract}

The investigation consisted in the interpretation of images recorded by a Side Scan Sonar at dredging dump areas of the Port of Itajaí (SC), South Brazil, and the relationship with the hydrodynamics. The study area corresponds to two regions located on the Inner continental shelf destined for the sediment dump areas, one located in front of Navegantes (BF-Norte) and the other in front of Brava Beach, municipality of Itajaí (BF-South). The equipment used was EdgeTech, Model $4200 \mathrm{HFL} 300 / 600 \mathrm{kHz}$ and the images were analyzed in order to identify the different patterns of reflection. Data of bottom currents; and significant wave heights, peak period e direction, from two Acoustic Doppler Current Profiler (ADCP) moorings), during the period from October 31 st to December 3rd, 2019, was also analyzed. Data. The bottom forms formed by fluxes resulting from the propagation of waves on the ocean surface are responsible for generating orbital movement of water particles along the seabed that fall perpendicular to the coast in shallow water conditions. The prevailing types of bottom class seen were sandy-muddy, muddy-sandy, sandy and coarse sand. Was identified structures had megaripple with a wavelength of approximately $0.95 \mathrm{~m}$ to $1.22 \mathrm{~m}$ corresponded to a bidirectional oscillatory flux governed by waves with a predominantly East direction in BF-North and waves with an East and Southeast direction in BFSouth. Undefined accumulations of sediments originating from the operation of the dredger when opening the cisterns were also identified. However, only waves with periods equal to or greater than 15 s generate flows close to the bottom capable of remobilizing and transporting sandy sediment at any depth of the BF-South. The sedimentary processes of the seafloor in the period of investigation were mainly governed by fluxes induced by waves, then by currents generated by winds and tidal currents. The BF-North reached higher bottom current velocity thresholds of $45 \mathrm{~cm} / \mathrm{s}$ and the BF-South $40 \mathrm{~cm} / \mathrm{s}$. 